\title{
Two strategies for improving animal farm wastewater treatment in reed beds
}

\author{
A. O. Babatunde and Y. Q. Zhao* \\ Centre for Water Resources Research, School of Architecture, Landscape and \\ Civil Engineering, Newstead Building, University College Dublin, Belfield, \\ Dublin 4, Ireland \\ "Corresponding author: Tel: +353-1-7163215, Fax: +353-1-7163297 \\ E-mail: yaqian.zhao@ucd.ie
}




\section{Abstract}

In this study, dewatered alum sludge cakes were used as substrate in a laboratory scale tidal vertical flow reed bed system treating animal farm wastewater. The "tidal flow" operation was employed to enhance oxygen transfer into the reed bed system, while dewatered alum sludge cake was used to enhance phosphorus (P) removal in the system through ligand exchange. Except for the removal of $\mathrm{P}$ which was consistently high throughout the experiment, the removal of organics $\left(\mathrm{BOD}_{5}, \mathrm{COD}\right)$ exhibited a trend of gradual and increasing removal. This highlights the obvious advantage of the use of the dewatered alum sludge cake in the reed bed. For the removal of organics, a mean removal percentage of $82.3 \pm 3.5 \%$ was obtained for $\mathrm{BOD}_{5}$ at an average loading of $84.6 \mathrm{~g} / \mathrm{m}^{2} . \mathrm{d}$. In addition, the first-order kinetics constant for $\mathrm{BOD}_{5}$ removal $\left(\mathrm{K}_{\mathrm{BOD}}, \mathrm{m} / \mathrm{d}\right)$ obtained in the system was about 9 times the rate constant commonly obtained in conventional horizontal flow systems. The mean level of dissolved aluminium (Al) monitored in the effluent was $0.04 \pm 0.01 \mathrm{mg} / \mathrm{l}$ and this is well below the discharge limit of $0.2 \mathrm{mg} / \mathrm{l}$ for $\mathrm{Al}$ discharge into all waters. 
Keywords: Alum sludge, Animal farm wastewater, Constructed wetlands, Phosphorus, Reed beds, Tidal flow

\section{Introduction}

Animal farming and production are key components of agriculture worldwide due to their strategic importance for both food stability and economic health. However, there are increasing environmental concerns and problems associated with the current scale of animal farming and production. These include nuisance odours, pathogens, concentrated wastewater, inadequate land treatment sites, residential encroachment and new regulations (Hunt and Poach, 2001). In particular, the steady intensification of such farming practices have led to increasing levels of environmental pollution, including degradation of the water quality of downstream ecosystems. For instance, in Ireland where about $25 \%$ of the land area is devoted to dairy farming, a survey of 1132 rivers and streams from 2001 to 2003 estimated that the percentage of pollution attributed to agriculture was approximately $32 \%, 32 \%$ and $15 \%$ respectively in rivers and streams which were slightly, moderately, and seriously polluted (Toner et al., 2005; Healy et al., 2007). Similarly in the UK, Brewer et al. (1999) reported that dairy farming accounts for the majority of the water pollution incidences arising from farm wastes. In the US, it was reported that $43 \%$ of Nitrogen $(\mathrm{N})$ and $60 \%$ of 
Phosphorus (P) input to the Upper Potomac basin, Maryland, came from animal waste (Cronk 1996). It is well known that the release of $\mathrm{P}$ from wastewaters into watercourses can cause severe pollution problems, such as eutrophication which frequently results in algal blooms, fish kills and loss of water resources. Therefore, it is very crucial to ensure efficient $\mathrm{P}$ removal during wastewater treatment.

The attribution of specific pollution incidences to animal farming can be explained by the common method of waste treatment and disposal on these farms. As the essential task of the farmer is to produce food, very few farms have the manpower, finance and technical competence to manage complicated effluent treatment operations similar to those that are employed in the process industries. Hunt and Poach (2001) reported that the common practice on most animal farms is to apply both solid and liquid waste to land for terminal treatment. In Ireland, it is reported that dairy parlour washings are treated mainly by land spreading with low irrigation systems (Healy et al., 2007). This is similar to the situation in the UK as noted by Brewer et al. (1999) and Tyrrel and Leeds-Harrison (2005). It was reported that dirty water from dairy farms was typically disposed of by application to land using low rate irrigators with perhaps no prior treatment. Such method of land spreading/application of wastes may initiate water pollution through surface run-off particularly when the soil is slow-draining and on a sloping land. In 
addition, during periods when the fields are fully saturated with rainfall, the effluents quickly gets into the water environment.

Thus, the need to seek alternative ways to treat their waste, coupled with increasing public concerns and stricter environmental legislations, have resulted in considerable pressure for farmers to prevent the pollution of the environment on their farms. This has led to considerable interest in simple, farmer friendly methods for the treatment of agricultural effluents. Such methods have included aerobic and anaerobic lagoons (Cronk, 1996), soil based treatment systems (Tyrrel and Leeds-Harrison, 2005), intermittent sand filtration systems (Healy et al., 2007) and constructed wetland systems (CWs). In particular, reed bed treatment systems (RBTSs) (a form of CWs planted with reeds) offer a cost-effective treatment option for such wastewaters and their use for the treatment of animal farm wastewaters have emerged strongly in the last decade. Hunt and Poach (2001) reported that there are at least 26 states in the US where livestock producers are using CWs to treat animal wastewaters. Several authors have also reported on the use of CWs/RBTSs for the treatment of animal farm wastewater (Copper and Testa, 1997; Reddy et al., 2000, Hunt and Poach, 2001; Zhao et al., 2004).

However, despite the increasingly widespread adoption of CWs/RBTSs for animal farm wastewater treatment, two key outstanding issues are still very 
critical to their successful implementation. These are oxygen transfer and $\mathrm{P}$ removal. Firstly, due to the fact that animal farming operations give rise to several effluents which are far stronger than those normally encountered in sewage works treating domestic wastewater, they exert a corresponding high oxygen demand on any system used for their treatment. For instance, dairy parlour washings can have a 5-day Biochemical Oxygen demand of about $2000 \mathrm{mg} / \mathrm{l}$ (Gray et al., 1990). The cost-effective treatment of such dairy parlour washings wastewater using the conventional CWs/RBTSs may not be economically and technically feasible. For instance, Sun et al. (1998a) attempted to treat a high strength agricultural wastewater with a significantly high $\mathrm{BOD}_{5}$ value using a horizontal-flow CWs. It was realised that due to insufficient oxygenation, the horizontal-flow CWs was unable to adequately reduce the $\mathrm{BOD}_{5}$ of the effluents for them to be discharged to watercourses. This is also in agreement with the findings of Hunt et al. (2003) in which it was stated that despite the effectiveness of CWs/RBTSs, their capacity to remove wastewater nitrogen and oxygen-demanding substances is limited by the oxygen availability in the wastewater and in the wetland soil.

Secondly, P removal from such high strength wastewaters when treated in CWs still remains to be optimised. Although $\mathrm{P}$ removal in a CWs/RBTSs can occur through a variety of processes, it is now generally acknowledged that sorption to the bed media is mainly responsible for long term and significant $\mathrm{P}$ 
removal (Babatunde, 2007). Conventional media used in CWs/RBTSs include sands, gravel and local soils. However, given the relatively high levels of $\mathrm{P}$ in such animal farm wastewaters, and the limited P removal capacity of the gravel or sands/local soils used, P removal is often reported to be poor. In response to these two key outstanding issues, two strategies were employed in this laboratory scale study to enhance the treatment of animal farm wastewater in RBTSs: (1) Dewatered alum sludge cakes was used as the main substrate as opposed to the conventional media of gravel, sands and local soils. Dewatered alum sludge is a by product of water treatment plants which uses aluminium sulphate as coagulant. Being very rich in aluminium, it has a high propensity to bind $\mathrm{P}$ in wastewaters. The case for the use of the dewatered alum sludge cakes as P-removing media during wastewater treatment in a CWs/RBTSs was first highlighted in our global review on beneficial reuse of waterworks sludges (Babatunde and Zhao, 2007), and such use has also been preliminarily demonstrated in our past study (Zhao et al., 2008); (2) Tidal flow strategy was employed to enhance the oxygen transfer efficiency of the RBTSs and thus improve its capability to treat high oxygen demanding wastewaters such as animal farm wastewaters. Tidal flow strategy refers to the rhythmical filling and draining of RBTSs matrices with wastewater, during which atmospheric diffusion of air is promoted and aerobic decomposition process is greatly enhanced (Green et al. 1997; 1998). This study presents results 
from a laboratory scale tidal vertical flow reed bed system employing these two strategies to enhance $\mathrm{P}$ removal and oxygen transfer during the treatment of an animal farm wastewater.

\section{Materials and methods}

Dewatered alum sludge cakes were collected from the mechanical dewatering unit of a water treatment plant (with ultimate water treatment capacity of $4 \times 10^{5}$ $\mathrm{m}^{3} / \mathrm{d}$ ) located in South-west Dublin, Ireland. The plant uses aluminum sulphate for raw water flocculation at a typical dose of $42-60 \mathrm{mg} / \mathrm{l}$. Specific characteristics of the dewatered alum sludge that are relevant to its use as a CWs/RBTSs substrate and as a plant growth medium have been examined in detail (Babatunde et al., 2009). A laboratory scale reed bed system was then set up using a $144 \mathrm{~mm}$ diameter (internal) Pyrex column filled firstly to $100 \mathrm{~mm}$ in depth with $10 \mathrm{~mm}$ gravel to serve as support and then packed to $350 \mathrm{~mm}$ with the ground sludge cakes. Fig. 1 shows a schematic diagram of the set-up of the lab-scale reed bed system. Phragmites australis were obtained from a commercial supplier and planted on top of the ground sludge. Wastewater with average concentration of 70 $\mathrm{mg} / \mathrm{l}(\mathrm{P}), 510 \mathrm{mg} / \mathrm{l}(\mathrm{SS}), 1150 \mathrm{mg} / \mathrm{l}(\mathrm{COD})$ and $750 \mathrm{mg} / \mathrm{l}\left(\mathrm{BOD}_{5}\right)$ was collected periodically from the secondary holding tank of an animal farm, which includes 
about 2000 livestock units of sheep, pigs, cattle and horses. The wastewater from all the activities on the farm is firstly collected and stored in a central facility where it undergoes primary sedimentation.

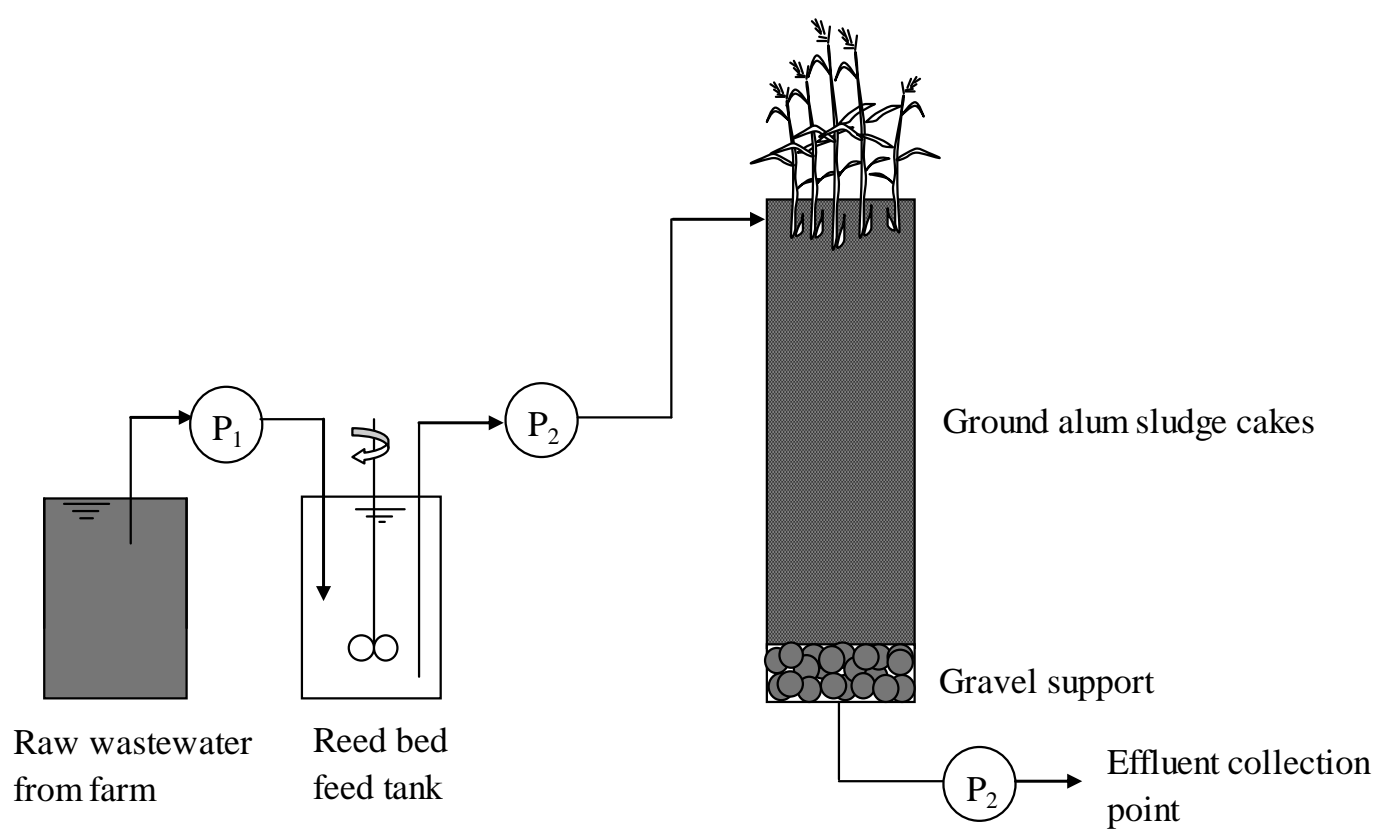

Fig.1. Schematic illustration of the set-up of the lab-scale reed bed system $\left(\mathrm{P}_{1}\right.$ and $\mathrm{P}_{2}$ refers to manually and timer controlled pumps respectively)

Thereafter, the wastewater is pumped to the secondary holding tank and then spray-irrigated on open fields. The collected wastewater (with or without dilution with tap water to achieve desired concentrations) was loaded onto the reed bed system via a feed tank at a daily flow rate of $0.008 \mathrm{~m}^{3} / \mathrm{d}$ giving a hydraulic 
loading rate of $0.5 \mathrm{~m}^{3} / \mathrm{m}^{2}$.d. The treatment system was operated using the tidal flow strategy and this was achieved by rhythmically filling and draining the reed bed matrices with wastewater. The rhythmical filling and draining generated the tides and this was realised using peristaltic pumps which were controlled by a preset electronic timer. The rhythmical operation was carried out in cycles during which the wastewater is drained out from the bed and the system is allowed to rest before the next cycle commences. The surface loadings (mean \pm SD) in each of the respective periods of operation (See table 1) range from $35.8 \pm 8.5 \mathrm{~g} / \mathrm{m}^{2} . \mathrm{d}$ to $111.7 \pm 13 \mathrm{~g} / \mathrm{m}^{2} . \mathrm{d}\left(\mathrm{BOD}_{5}\right), 66.7 \pm 21 \mathrm{~g} / \mathrm{m}^{2} . \mathrm{d}$ to $183.6 \pm 11 \mathrm{~g} / \mathrm{m}^{2} . \mathrm{d}(\mathrm{COD})$ and $3.3 \pm$ $1.3 \mathrm{~g} / \mathrm{m}^{2} . \mathrm{d}$ to $10.3 \pm 1.3 \mathrm{~g} / \mathrm{m}^{2} . \mathrm{d}(\mathrm{RP})$. Samples of influent and effluent from the reed bed system were collected at least once each week and analysed periodically for $\mathrm{BOD}_{5}$ (using Hach BODTrack Apparatus), COD, P, SS and effluent Al (using Hach DR/2400 spectrophotometer).

The $\mathrm{P}$ analysis was based on the reaction of orthophosphate in the samples with molybdate in an acid medium to produce a mixed phosphate/molybdate complex. In the presence of vanadium, yellow molybdovanadophosphoric acid is formed whose colour intensity is proportional to the phosphate concentration. The concentration is then determined indirectly using the spectrophotometer. The $\mathrm{P}$ analysis was done in two parts: (1) Samples were directly reacted (without filtration) with the reagent and analysed to determine the reactive P (RP) and (2) 
Samples were filtered using a $0.45 \mu \mathrm{m}$ membrane filter and the filtrate was analysed to determine the soluble reactive P (SRP). In order to monitor biofilm development, examine the removal of $\mathrm{P}$ from the wastewater and also observe any change of surface characteristics, surfaces of the fresh alum sludge particles (referred to as clean sludge) and the sludge particles that were used in the system (referred to as used sludge) were examined under a scanning electron microscope (SEM) and a SEM-EDX (SEM energy dispersive X-ray, INCAx - Sight model 6587, Oxford instruments, UK). For the SEM examination, the samples were precoated with gold for specified minutes before being examined under the SEM.

\section{Results}

\subsection{Overall treatment performance}

Fig. 2 illustrates the removals (in percentage reduction) of $\mathrm{COD}, \mathrm{BOD}_{5}$ and $\mathrm{P}$ in the system. The respective pollutant loadings across the different periods of operation and the corresponding progressive mean treatment performance results $( \pm$ SD) obtained is presented in Table 1. Fig. 2 shows that while the removal of organics in the system increased gradually with time, the removal of P was very high in the initial stages and also throughout the experimental period. Both RP and SRP were efficiently removed in the system, although the removal of SRP was slightly higher than RP. Overall, pollutant removal efficiencies up to $85.5 \pm$ 
$2.1 \%(\mathrm{COD})$ and $82.3 \pm 3.5 \%\left(\mathrm{BOD}_{5}\right)$ were achieved in the system. However, $\mathrm{P}$ removal efficiency was up to $93.7 \pm 0.8 \%$ (SRP) and $88.1 \pm 0.5 \%$ (RP). By examining data on the removal of $\mathrm{SS}, \mathrm{COD}$ and $\mathrm{BOD}_{5}$ during the initial stages $(<$ 8 weeks), it can be suggested that the initial removal of the carbonaceous substrates is through filtration while improved removal was obtained gradually through aerobic degradation as the system stabilized and matured. As the experiment progressed and the system further stabilized, the removal of organics became considerably significant in the system even at higher loadings (Table 1).

P-removal was however consistently high throughout the experimental duration as opposed to the removal of organic matter which was gradual. As earlier noted, SRP was efficiently removed from the system. This is unusual in conventional $\mathrm{CWs}$ as initial $\mathrm{P}$ removal is generally poor due to the poor $\mathrm{P}$ adsorption capacity of the gravel or other media used, and the fact that the other $\mathrm{P}$ removal mechanisms, such as biomass and plant uptake may take several months before they can significantly contribute to P removal. However, the dewatered alum sludge cake used herein is mainly composed of aluminium ions and this facilitates its ability to enhance $\mathrm{P}$ removal from wastewater through ligand exchange (Yang et al., 2006). Interestingly, the mean level of dissolved aluminium (Al) monitored in the effluent from the system was $0.04 \pm 0.01 \mathrm{mg} / \mathrm{l}$ and this is well below the discharge limit of $0.2 \mathrm{mg} / \mathrm{l}$ for $\mathrm{Al}$ discharge into all 
waters. The release or non-release of aluminium during the reuse of alum sludge is a critical issue from the environmental safety point of view and it is thus very important to observe that aluminium levels in the effluents were below the discharge limit.
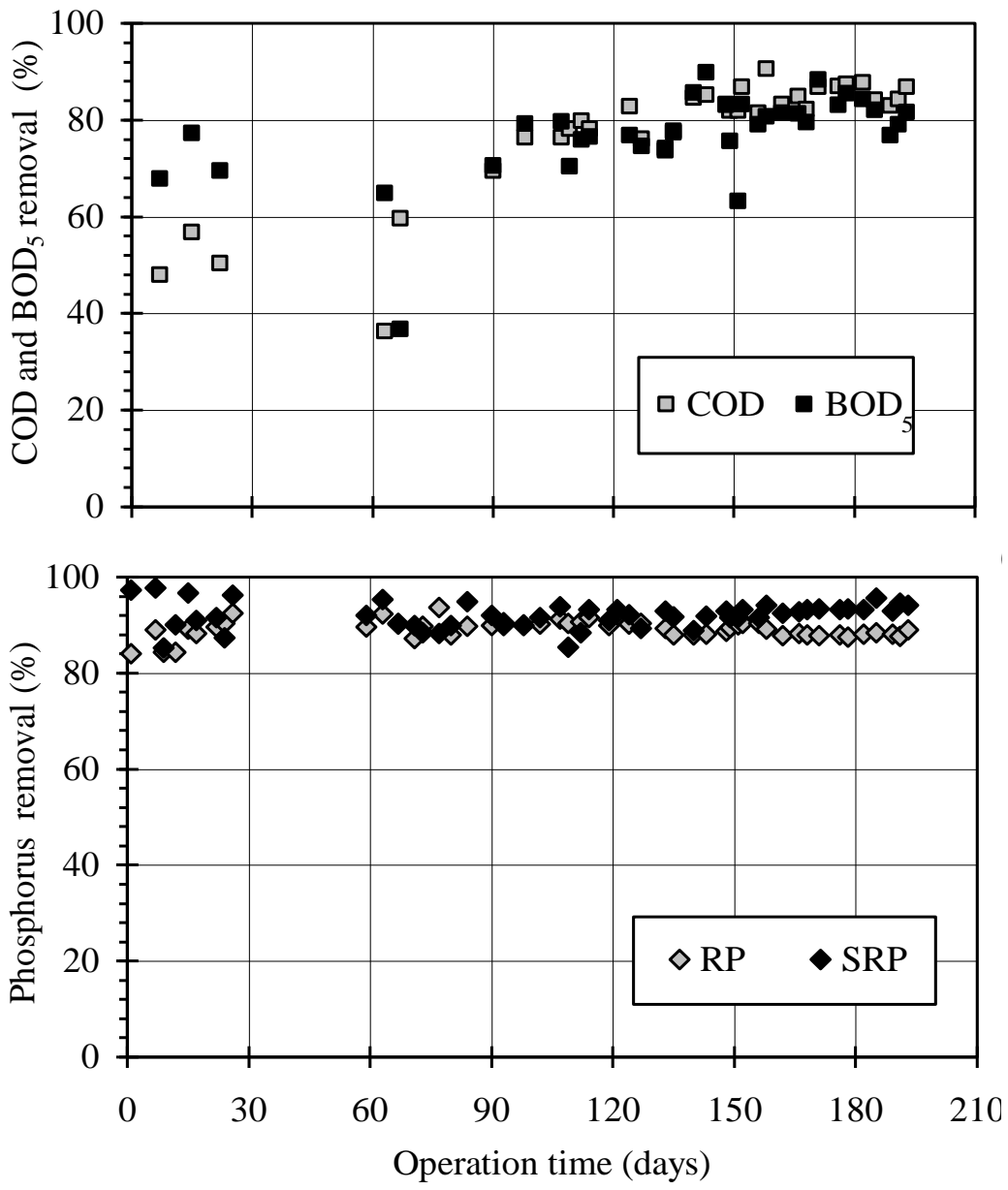

Fig. 2. Removal trend of pollutants in the reed bed treatment system 
Table 1 Pollutant loading and treatment efficiency during the different operational period in the reed bed system

\begin{tabular}{|c|c|c|c|c|c|c|}
\hline & \multirow{2}{*}{ Parameter } & \multicolumn{5}{|c|}{ Period (Weeks) } \\
\hline & & $1-8$ & $9-12$ & $13-16$ & $17-20$ & $21-28$ \\
\hline \multirow{3}{*}{$\mathrm{BOD}_{5}$} & $\mathrm{n}$ & 5 & 4 & 6 & 10 & 9 \\
\hline & loading $\left(\mathrm{g} / \mathrm{m}^{2} . \mathrm{d}\right)$ & $35.8 \pm 8.5$ & $50.0 \pm 6.7$ & $57.5 \pm 10$ & $114.8 \pm 15$ & $111.7 \pm 13$ \\
\hline & $\%$ removal & $63.3 \pm 16$ & $71.7 \pm 5.2$ & $75.9 \pm 1.4$ & $80.3 \pm 7.1$ & $82.3 \pm 3.5$ \\
\hline \multirow{3}{*}{ COD } & $\mathrm{n}$ & 5 & 4 & 6 & 10 & 9 \\
\hline & loading $\left(\mathrm{g} / \mathrm{m}^{2} . \mathrm{d}\right)$ & $66.7 \pm 21$ & $77.1 \pm 12$ & $99.4 \pm 13$ & $187.6 \pm 25$ & $183.6 \pm 11$ \\
\hline & $\%$ removal & $50.2 \pm 9.1$ & $75.1 \pm 3.8$ & $78.0 \pm 3.1$ & $84.4 \pm 2.8$ & $85.5 \pm 2.1$ \\
\hline \multirow{3}{*}{$\mathrm{RP}$} & $\mathrm{n}$ & 16 & 7 & 8 & 10 & 9 \\
\hline & loading $\left(\mathrm{g} / \mathrm{m}^{2} . \mathrm{d}\right)$ & $3.3 \pm 1.3$ & $4.7 \pm 0.9$ & $6.0 \pm 1.3$ & $8.4 \pm 1.3$ & $10.3 \pm 1.3$ \\
\hline & $\%$ removal & $88.9 \pm 2.9$ & $90.2 \pm 0.5$ & $90.3 \pm 1.3$ & $89.0 \pm 1.0$ & $88.1 \pm 0.5$ \\
\hline \multirow{3}{*}{ SRP } & $\mathrm{n}$ & 16 & 7 & 8 & 10 & 9 \\
\hline & loading $\left(\mathrm{g} / \mathrm{m}^{2} . \mathrm{d}\right)$ & $1.85 \pm 0.7$ & $2.37 \pm 0.7$ & $2.91 \pm 1.2$ & $3.93 \pm 2.0$ & $4.89 \pm 0.9$ \\
\hline & $\%$ removal & $91.7 \pm 3.8$ & $91.1 \pm 3.1$ & $91.5 \pm 1.8$ & $92.1 \pm 1.4$ & $93.7 \pm 0.8$ \\
\hline \multirow{3}{*}{ SS } & $\mathrm{n}$ & 16 & 7 & 8 & 10 & 9 \\
\hline & loading $\left(\mathrm{g} / \mathrm{m}^{2} \cdot \mathrm{d}\right)$ & $23.9 \pm 2.9$ & $36 \pm 1.3$ & $38.1 \pm 1.7$ & $75.6 \pm 5.5$ & $84.6 \pm 3.3$ \\
\hline & $\%$ removal & $76.4 \pm 20$ & $79.8 \pm 14$ & $83 \pm 9.2$ & $86 \pm 12.7$ & $91.7 \pm 3.2$ \\
\hline
\end{tabular}

$n$ refers to the number of samples 


\subsection{The effect of the tidal flow strategy on the treatment performance}

In order to examine the effect of the tidal flow strategy on the system, the theoretical oxygen transfer rate of the system was computed. A value 137.2 $\mathrm{g} / \mathrm{m}^{2} . \mathrm{d}$ was calculated using equation (1). Equation (1) is hinged on the knowledge that the volume of air drawn into the reed bed matrices will be equal to the volume of the drained wastewater (Green et al., 1998). Therefore, based on the perfect gas equation at $20^{\circ} \mathrm{C}$ and atmospheric pressure, the theoretical oxygen supply (TOS) into the system across its surface area was determined as:

$$
\operatorname{TOS}=\frac{0.21\left[\frac{\mathrm{O}_{2}}{\text { Air }}\right] \times 1[\mathrm{~atm}] \times 32\left[\frac{\mathrm{g}}{\mathrm{mole}}\right] \times 8\left[\frac{\mathrm{L}}{\mathrm{d}}\right]}{0.082\left[\frac{\mathrm{L} \times \mathrm{atm}}{\mathrm{mol} \times \mathrm{K}}\right] \times 293\left[{ }^{\circ} \mathrm{K}\right] \times 0.0163\left[\mathrm{~m}^{2}\right]}=137.2 \quad \mathrm{~g}-\mathrm{O}_{2} / \mathrm{m}^{2} \cdot \mathrm{d} \quad \text { Eq. (1) }
$$

Correlation charts between (i) $\mathrm{BOD}_{5}$ loading rates and the effluent $\mathrm{BOD}_{5}$ values and (ii) the loading and removal rates for $\mathrm{BOD}_{5}$ were obtained and presented in Fig. 3. From the figure, it can be seen that in the current system, there was no strong relationship exhibited between the $\mathrm{BOD}_{5}$ loading rates and the effluent $\mathrm{BOD}_{5}$ values as shown by the $\mathrm{R}^{2}$ value of 0.46 . However, on the other hand, it can be seen that the removal rate of $\mathrm{BOD}_{5}$ increased with increase in the loading rate and a very strong relationship was obtained with a $R^{2}$ value of 0.95 . This demonstrates a key advantage of the system over conventional reed bed 
systems at similar stage of operation. In typical cases, the efficiency decreases, (i.e., effluent concentration increases proportionately) as the loading is increased. For instance, Christos and Vassilios (2007) observed that since higher loading implies a smaller hydraulic retention time, then efficiency will expectedly decrease leading to increase in effluent concentration.

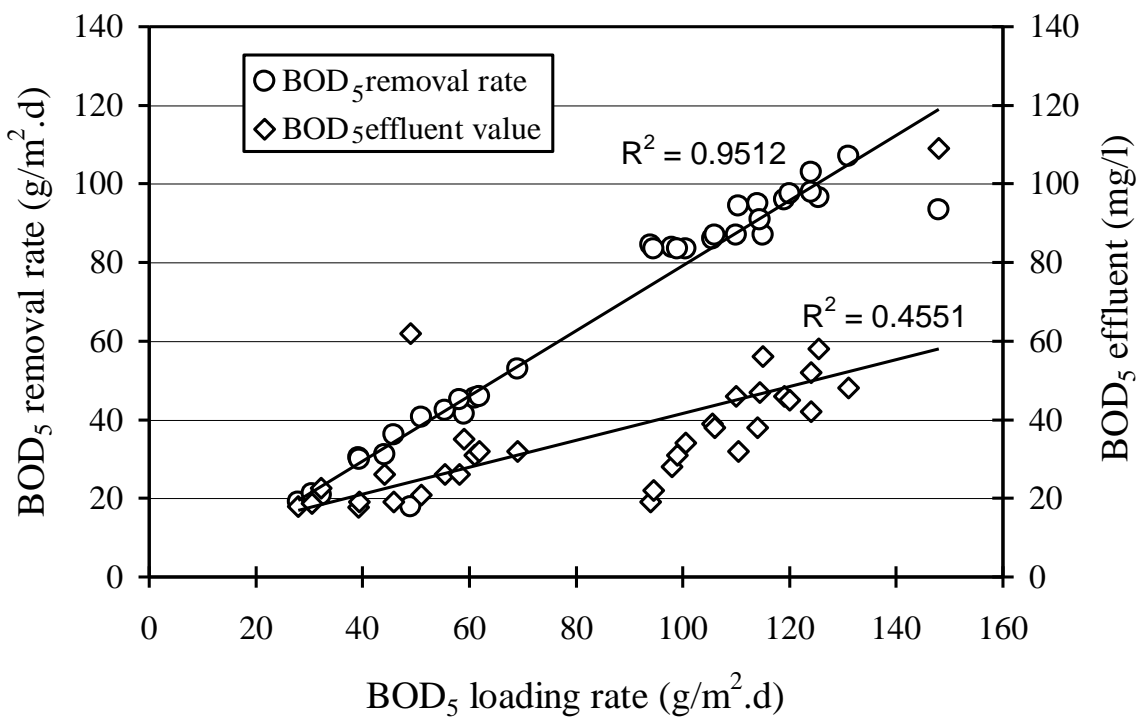

Fig. 3. Correlations between $\mathrm{BOD}_{5}$ loading and effluent $\mathrm{BOD}_{5}$ values as well as $\mathrm{BOD}_{5}$ removal rates

However, the results obtained in this study indicate increase in $\mathrm{BOD}_{5}$ removal rate as the loading rate increases and this can be explained by the effect of the tidal flow strategy. Generally, it is known that the amount of soluble oxygen in wastewaters and biofilms is usually limited, and cannot support intensive 
microbial activities when high strength wastewaters are treated. Consequently, since during wastewater treatment in CWs/RBTSs, organic matter is retained due to biomass accumulation, then it can be postulated that the enhanced oxygen transfer rate of the tidal flow strategy serves to significantly enhance aerobic decomposition in the system. In essence, the enhanced oxygen supply of the tidal flow strategy can enable the treatment of high strength wastewaters with significant performance even at higher concentrations in CWs. The fact that the $\mathrm{BOD}_{5}$ loading rate showed a stronger correlation with the $\mathrm{BOD}_{5}$ removal rate than with the effluent $\mathrm{BOD}_{5}$ values implies that the obvious and significant benefit of the tidal flow strategy is the reduction in the footprint necessary for treatment due to its enhanced oxygen transfer efficiency. In the current system, it can be seen that improved performance and removal rate was obtained even at higher loadings (See Table 1), and this highlights the effect of the tidal flow strategy.

\subsection{Results of SEM and SEM-EDX imaging}

SEM and SEM-EDX images of the sludge samples are shown in Fig. 4. The result clearly demonstrates (i) the change of the surface characteristics of the alum sludge, with the surface of the used sludge now being covered with slimes, which is likely from biomass/solids deposition on the surface and microbial development 
in the sludge matrix and (ii) the removal of $\mathrm{P}$ from the wastewater onto the surface of the used alum sludge.
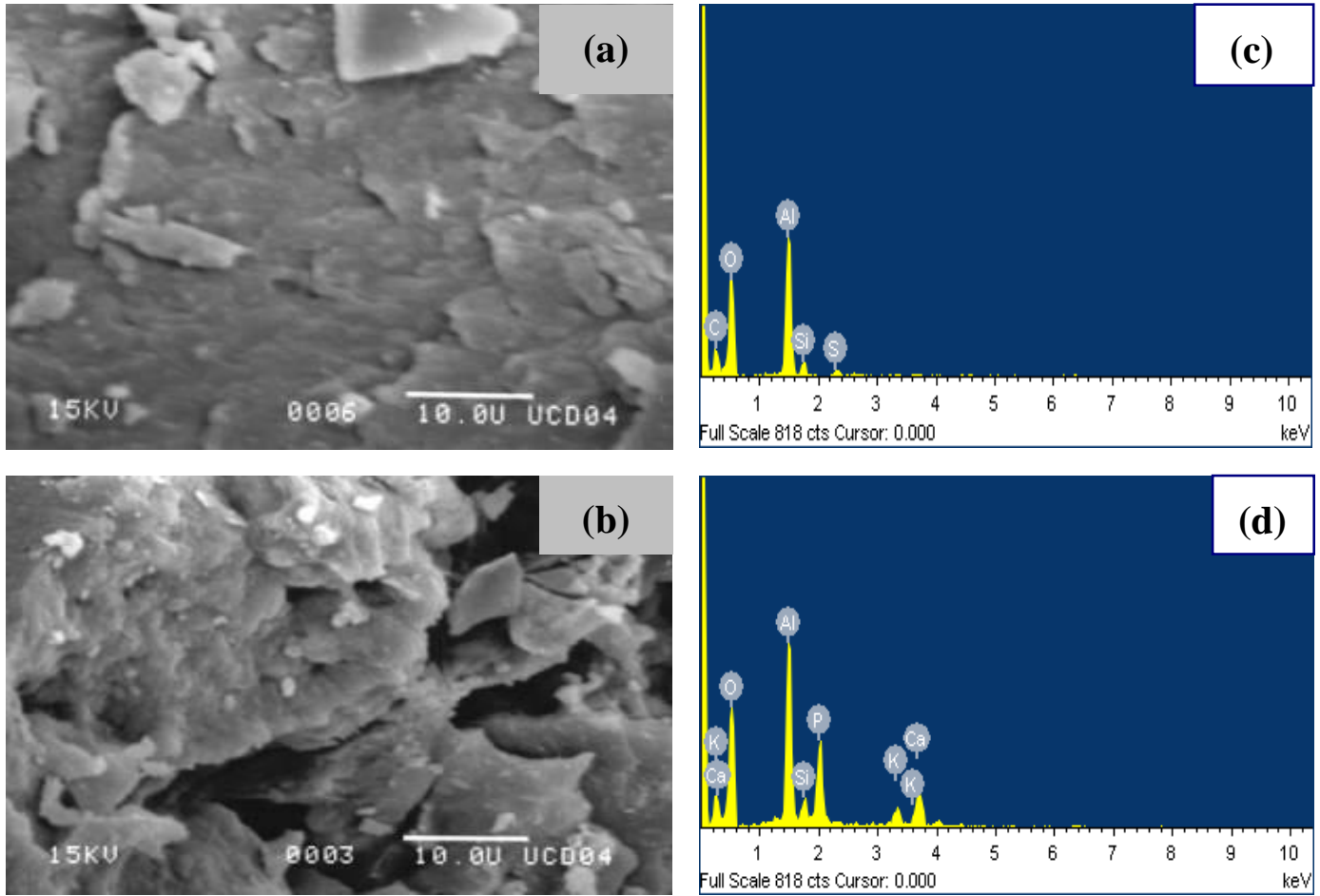

Fig. 4. SEM (2000×magnification) and SEM-EDX images of surfaces of clean alum sludge (Fig. $4 a$ and $c$ respectively) and used alum sludge (Fig. $4 b$ and $d$ respectively) 


\section{Discussion}

For the treatment of animal farm wastewaters in RBTSs, the need for intensified oxygen flux into the system and enhanced P removal can hardly be overemphasized. Vertical flow beds employing the tidal flow strategy have however been developed and demonstrated to enhance oxygen supply (Green et al., 1998; Scholz and Xu, 2002; Zhao et al., 2004; Lee and Scholz, 2006), making them a viable system for the treatment of such wastewaters. In this study, the BOD $_{5}$ loading varied from $35.8 \pm 8.5 \mathrm{~g} / \mathrm{m}^{2}$.d to $111.7 \pm 13 \mathrm{~g} / \mathrm{m}^{2} . \mathrm{d}$. Clearly, the reed plants could not provide sufficient oxygen for aerobic degradation in the system which would have accounted for the high levels of organic matter removal obtained in the system. This is because the potential oxygen release from the roots of Phragmites is no more than $0.02 \mathrm{~g} / \mathrm{m}^{2} . \mathrm{d}$ (Brix, 1990). Similarly, if the wastewater were to be treated in a conventional horizontal flow RBTSs/CWs, the level of organic matter removal obtained in the current system may not have been achieved, since the oxygen flux obtainable in a horizontal flow reed bed is reported to be less than $20 \mathrm{~g}-\mathrm{O}_{2} / \mathrm{m}^{2}$.d (Reed et al., 1998).

The tidal flow concept refers to the rhythmical filling of the reed bed matrices with wastewater and then subsequently draining it. This allows for maximum pollutant biofilm contact during the fill stage. As the wastewater is being drained 
from the system, the draining water acts as a passive pump, which draws atmospheric air into the matrices, thus replenishing the biofilm with oxygen. As can be seen from Table 1, removal of organics improved steadily with operation time across the different periods of operation, with removal efficiencies up to $82.3 \pm 3.5 \%\left(\mathrm{BOD}_{5}\right)$ and $85.5 \pm 2.1 \%(\mathrm{COD})$ achieved in the system. The slimy covering on the surfaces of the used sludge (Fig. $4 b \& d$ ) as compared to the surfaces of the clean sludge (Fig. $4 a \& c$ ), suggests biomass development, which reflects both the suitability of the system for the growth and activities of microorganisms and intense biological activity in the system. Based on the tidal flow concept, a TOS rate of $137.2 \mathrm{~g} / \mathrm{m}^{2} . \mathrm{d}$ was calculated for the system. In comparison to the oxygen demand on the system, the tidal flow strategy can be seen to have the potential to enhance treatment efficiency with substantial reductions obtained even at higher loadings. The strong relationship between loading and removal rate for $\mathrm{BOD}_{5}$ as shown in Fig. 3 indicates that with the enhanced oxygen supply of the tidal flow strategy, it will be possible to treat high strength wastewaters and obtain improved performance even at higher concentrations.

In this study, at a mean influent $\mathrm{BOD}_{5}$ concentration of $169.2 \pm 70.6 \mathrm{mg} / \mathrm{l}$, corresponding to a mean $\mathrm{BOD}_{5}$ loading of $84.6 \mathrm{~g} / \mathrm{m}^{2} . \mathrm{d}$, an average $76.9 \%$ reduction which gives an average removal rate of $66.4 \mathrm{~g} / \mathrm{m}^{2} . \mathrm{d}$ was achieved. In a 
similar study employing the tidal flow mechanism, Sun et al. (1998b) reported a $99.1 \%$ reduction from an average influent $\mathrm{BOD}_{5}$ concentration of $464 \mathrm{mg} / \mathrm{l}$ giving a removal rate of $71.9 \mathrm{~g} / \mathrm{m}^{2}$.d. The high removal efficiency obtained in both cases reflects the enhanced oxygen supply of the tidal flow strategy, which results in better treatment performance even at higher concentrations. It should be noted that the hydraulic and organic loadings $\left(\mathrm{BOD}_{5}\right)$ used in this study which are 0.45 $\mathrm{m}^{3} / \mathrm{m}^{2} . \mathrm{d}$ and $35.8-111.7 \mathrm{~g} / \mathrm{m}^{2} . \mathrm{d}$ respectively, are considerably higher than the typical loadings on subsurface horizontal or vertical flow CWs/RBTSs. Weedon (2003) reported that in typical compact vertical flow systems, the hydraulic and organic loadings are $0.039 \mathrm{~m}^{3} / \mathrm{m}^{2} . \mathrm{d}$ and $13.7 \mathrm{~g} \mathrm{BOD}_{5} / \mathrm{m}^{2} . \mathrm{d}$ respectively. However, the loadings used in this study are quite comparable to those used in other similar studies employing the tidal flow strategy i.e. Zhao et al. (2004) and Sun et al. (2006). Notwithstanding the relative high loadings used in this study, the performance results obtained compare very well with CWs in other European countries where organic substances are reported to be typically removed by 80-99 $\%$ and inorganic nutrients removed by about $50 \%$ in the long run (Verhoeven and Meuleman, 1999; Sun et al., 2006).

The first order kinetics rate constant for BOD removal $\left(\mathrm{K}_{\mathrm{BOD}}, \mathrm{m} / \mathrm{d}\right)$ for the current system was evaluated using mean values of the influent and effluent $\mathrm{BOD}_{5}$ concentrations and the Kickuth equation (Eq. 2). The $\mathrm{K}_{\mathrm{BOD}}$ was then compared 
with values for other systems. It should however be noted that while the Kickuth equation enables some form of comparison between $\mathrm{CWs}$, it is not recommended for the design of CWs treating strong effluents as there is no convincing evidence that the removal of organic matter in such CWs is indeed first-order.

$$
A_{h}=\frac{Q_{d}\left(\ln C_{o}-\ln C_{e}\right)}{K_{B O D}}
$$

where $A_{h}$ is the reed bed surface area $\left(\mathrm{m}^{2}\right), Q_{d}$ is the average daily flow rate of the wastewater $\left(\mathrm{m}^{3} / \mathrm{d}\right) ; \mathrm{C}_{\mathrm{o}}$ and $\mathrm{C}_{\mathrm{e}}(\mathrm{mg} / \mathrm{l})$ are influent and effluent $\mathrm{BOD}_{5}$ values respectively and $\mathrm{K}_{\mathrm{BOD}}$ is the rate constant $(\mathrm{m} / \mathrm{d})$ when the removal of organic matter is described by first-order kinetics.

A $K_{B O D}$ value of $0.87 \mathrm{~m} / \mathrm{d}$ was determined for the system in the current study and this is approximately 9 times the value of the rate constant obtainable in horizontal flow systems in the UK, which is reported to be about $0.067-0.1 \mathrm{~m} / \mathrm{d}$ (Schierup and Brix, 1990; Copper et al., 1996). The $\mathrm{K}_{\mathrm{BOD}}$ value obtained in this study is also quite comparable to the $\mathrm{K}_{\mathrm{BOD}}$ values of $0.28-0.93 \mathrm{~m} / \mathrm{d}$ obtained by Sun et al. (2005) in a similar study. The relatively higher value of the $\mathrm{K}_{\mathrm{BOD}}$ reflects the enhanced performance and the more efficient degradation of organic 
matter in the tidal flow system, and this can be attributed to the enhanced oxygen transfer capability of the tidal flow system.

However, what remains to be seen is the treatment performance of the system when the $\mathrm{BOD}_{5}$ loading rate equals and/or exceeds the theoretical oxygen transfer rate of the tidal flow strategy. For instance, as can be seen from Fig. 3, the $\mathrm{BOD}_{5}$ loading rate rarely exceeded the theoretical oxygen transfer rate limit of 137.2 $\mathrm{g} / \mathrm{m}^{2} . \mathrm{d}$ for the tidal flow strategy. Within this theoretical limit, a very strong relationship was obtained between the removal rate and the loading rate with the removal rate increasing as the loading rate increased. However, although the loading and removal obtained from the system are quite higher than in conventional systems, it is suggested that the system be examined beyond the theoretical limits of the oxygen transfer rate.

$\mathrm{P}$ removal in the system was consistently high as compared to the other pollutants. It is well known that $\mathrm{P}$ is a nutrient of concern during wastewater treatment in RBTSs and the media plays a dominant role in its removal. The process is believed to be through ligand exchange reaction in which phosphate displaces water or hydroxyl ions from the surface of iron and aluminium hydrous oxides (IWA, 2000). This provides justification for the use of the alum sludge cakes in the system, as the alum sludge used has an aluminium concentration of $42.67 \mathrm{mg}-\mathrm{Al} / \mathrm{g}$ (Babatunde, 2007), thus providing a high potential for ligand 
exchange reactions. As can be seen in Fig. 4, SEM images of the used alum sludge cake particles (Fig. 4c) suggest a slimy covering on the surface as opposed to the smooth surface of the clean sludge (Fig. 4a). By further examining the sludge particles using the SEM-EDX as shown in Fig. $4 b \& d$, a key difference noted is the observation of $\mathrm{P}$ on the surface of the used sludge particles. It can be explained that the abundance of aluminium ions in the sludge facilitated $\mathrm{P}$ removal from wastewater through ligand exchange. This is in agreement with the suggestions of Ippolito et al. (2003) which state that $\mathrm{P}$ retention by water treatment plant residual may be due to chemisorption, as $\mathrm{P}$ may be initially adsorbed as an outer sphere complex or found in the diffuse ion swarm near the individual sludge particles.

Removal of SS was equally high and it ranged from $76.4 \pm 2.0 \%$ to $91.7 \pm 3.2$ $\%$ respectively. This further indicates that the alum sludge acted as an excellent filter, lowering particulate pollutants concentration and thereby contributing to the overall treatment process. As anticipated, SS removal from the wastewater caused some build-up on the sludge surface, leading to a drop in the initial infiltration rate of wastewater into the system and subsequent ponding at the surface. It is well noted that the susceptibility of vertical flow reed beds to clogging is one of their very few drawbacks. In this particular case, possible combination with soil based constructed wetlands may minimise solids loads initially and then achieve 
concurrent high oxygenation and $\mathrm{P}$ reduction in the alum sludge vertical flow reed bed. Reed growth was disappointing during the first two months with the reeds turning yellow and growth stunted. New growth however appeared after about 81 days and continued thereafter, thus demonstrating that the dewatered sludge cakes can also be a potential growth medium for the reeds. On the possible release of aluminium from the alum sludge into the treated effluent, the mean concentration of soluble aluminium in the effluent was $0.04 \pm 0.01 \mathrm{mg}-\mathrm{Al} / \mathrm{l}$ and this is well below the prescribed limits of $0.2 \mathrm{mg} / \mathrm{l}$ for $\mathrm{Al}$ for discharge into all waters (Babatunde and Zhao, 2009). Furthermore, it has been shown that of all the elements/metals in the alum sludge, aluminium has the lowest leaching potential relative to the initial mass of the constituent present in the alum sludge (Babatunde and Zhao, 2009). As regards what to do with the sludge when it is used up (saturated with phosphorus and organic matter), it has to be emphasized that while eventual $\mathrm{P}$ saturation is inevitable, the amount of $\mathrm{P}$ that would have been removed in a cost effective manner would have been justified. In addition, such an approach may lead to a value added reuse option for the alum sludge cakes as there may be possibility of utilizing them as soil improvers in agriculture and/or P source for plants. It can be argued that if sewage sludge can be developed/conditioned and reused as biosolids in agriculture, then such use for alum sludges should also be feasible. Kvarnstrom et al. (2004) and Lena (2006) 
have both shown that upon saturation, $\mathrm{P}$ accumulated in constructed wetland substrates can be an effective $\mathrm{P}$ source for plants and the substrates can be used as soil improvers. On the other hand, it is possible to recover the $\mathrm{P}$ from the saturated sludge and this has been demonstrated by Zhao and Zhao (2009).

\section{Conclusions}

A lab-scale tidal vertical flow reed bed system was operated using dewatered alum sludge cakes as main substrate. Despite relatively high surface loadings of $\mathrm{P}$, removal efficiency up to $93.7 \pm 0.8 \%$ (soluble reactive phosphorus) was achieved during the 28 weeks of continuous operation. Mean concentration of soluble aluminium in the effluent was $0.04 \pm 0.01 \mathrm{mg}-\mathrm{Al} / \mathrm{l}$ and this is well below prescribed limits. Removal of organics improved steadily with time and removal efficiencies of $82.3 \pm 3.5 \%\left(\mathrm{BOD}_{5}\right)$ and $85.5 \pm 2.1 \%(\mathrm{COD})$ were achieved in the system. A first-order $\mathrm{K}_{\mathrm{BOD}}$ value of $0.87 \mathrm{~m} / \mathrm{d}$ was obtained in the system, and this is 9 times the $\mathrm{K}_{\mathrm{BOD}}$ value for horizontal flow systems in the UK. 


\section{Acknowledgement}

Authors are indebted to the Irish Environmental Protection Agency for financial assistance obtained for this study through the Environmental Technologies Scheme (project No. 2005-ET-S-7-M3).

\section{References}

Babatunde, A.O. (2007). The development of an alum sludge based tidal flow constructed wetland for optimizing phosphorus and organic matter removal from wastewaters. PhD dissertation, University College Dublin

Babatunde, A. O. and Zhao, Y. Q. (2007). Constructive approach towards water treatment works sludge management: An international review of beneficial re-uses. Critical Reviews in Environmental Science and Technology, 37, $129-164$

Babatunde, A.O. and Zhao, Y.Q. (2009). Leachability and leaching patterns from aluminium-based water treatment residual used as media in laboratory-scale engineered wetlands. Submitted to Environmental Science and Pollution Research

Babatunde, A.O., Zhao, Y.Q., Burke, A.M., Morris, M.A and Hanrahan, J.P (2009). Characterization of aluminium-based water treatment residual for potential phosphorus removal in engineered wetlands. Enviro. Pollu. 157, 2830-2836

Brewer, A.J., Cumby, T.R. and Dimmock, S.J. (1999). Dirty water from dairy farms, II: treatment and disposal options. Bioresource Technology, 67, 161169

Brix, H. (1990). Gas exchange through the soil-atmosphere interphase and through dead culms of Phragmites australis in a constructed reed bed receiving domestic sewage. Water Research, 24, 259-266.

Christos, S.A. and Vassilios, A.T. (2007). Effect of temperature, HRT, vegetation and porous media on removal efficiency of pilot-scale horizontal subsurface flow constructed wetlands. Ecological Engineering, 29, 173-191

Cooper, P.F., Job, G.D., Green, M.B., Shutes, R.B.E. (1996). Reed beds and constructed wetlands for wastewater treatment, WRc Publications,Swindon, 29-34

Cooper, C.M. and Testa, S. (1997). A constructed bulrush wetland for treatment of cattle waste. In: Constructed Wetlands for Animal Waste, E.P.A. Special 
Publication, Gulf of Mexico Program - Nutrient Enrichment Committee, Payne Engineering and CH2M Hill, pp.II.14-II.24.

Cronk, J.K. (1996). Constructed wetlands to treat wastewater from dairy and swine operations: a review. Agriculture Ecosystems Environment, 58, 97114.

Forbes, M.G., Dickson, K.L., Saleh, F., Waller, W.T., Doyle, R.D. and Hudak, P. (2005). Recovery and fractionation of phosphorus retained by lightweight expanded shale and masonry sand used as media in subsurface flow treatment wetlands. Environmental Science and Technology, 39, 4621-4627

Gray, K.R., Biddlestone, A.J., Job, G. and Galanos, E. (1990). The use of reed beds for the treatment of agricultural effluents. In: Constructed Wetlands in Water Pollution Control. Copper, P.F and Findlater, B.C. (eds). Pergamon press.

Green M, Friedler E, Ruskol Y and Safrai I. (1997). Investigation of alternative method for nitrification in constructed wetlands. Wat. Sci. \& Tech., 35(5), 63-70.

Green, M., Fiedler, E. and Safrai, I. (1998). Enhancing nitrification in vertical flow constructed wetland utilizing a passive air pump. Water Research, 32, 3513-3520.

Healy, M.G., Rodgers, M. and Mulqueen, J. (2007). Treatment of dairy wastewater using constructed wetlands and intermittent sand filters. Bioresource Technology, 98, 2268-2281

Hunt, P.G. and Poach, M.E. (2001). State of the art for animal wastewater treatment in constructed wetlands. Water Science \& Technology, 44, 19-25

Hunt, P.G., Matheny, T.A. and Szogi, A.A. (2003). Denitrification in constructed wetlands used for the treatment of swine wastewater. Environmental Quality, 32, 727-735

Ippolito, J.A., Barbarick, K.A., Heil, D.M., Chandler, J.P. and Redente, E.F. (2003). Phosphorus retention mechanisms of a water treatment residual. Environmental Quality, 32, 1857-1864

IWA (2000). Constructed wetlands for pollution control: Processes, Performance, Design and Operation. IWA Specialist Group on use of Macrophytes in Water Pollution Control. IWA Publishing, London, 155pp

Kvarnstrom, M.E., Morel, C.A.L. and Krodstad. (2004). Plant-availability of phosphorus in filter substrates derived from small-scale wastewater treatment systems. Ecological Engineering, 22, 1-15

Lee, B.-H. and Scholz, M. (2006). Application of the Self-organizing Map (SOM) to assess the Heavy Metal Removal Performance in Experimental Constructed Wetlands. Water Research, 40 (18), 3367-3374. 
Lena, J.W. (2006). Substrates for phosphorus removal-potential benefits for onsite wastewater treatment. Water Research, 40, 23-36.

Reed, S.C., Middlebrooks, E.J. and Crites, R.W. (1998). Natural systems for waste management and treatment. $1^{\text {st }}$ edition. McGraw-Hill, New York, USA.

Reddy, G.B., Hunt, P.G., Phillips, R., Stone, K.C. and Grubbs, A. (2000). Treatment of swine wastewater in marsh-pond-marsh constructed wetlands. Paper presented at the $7^{\text {th }}$ International conference on Wetland Systems for Water Pollution Control, 8pp

Schierup, H.H. and Brix, H. (1990). Danish experience with emergent hydrophyte treatment systems (EHTS) and prospects in the light of future requirements on outlet water quality. Water Science \& Technology, 22, 65-72.

Scholz, M. and Xu, J. (2002). Comparison of Constructed Reed Beds with Different Filter Media Treating Simulated Mine Drainage Water. Ecological Engineering, 18 (3), 385-390.

Sengupta, A.K. and Prakash, P. (2004). Alum recovery from water treatment works sludges, In: Global Focus on Sustainability, Water 21, IWA Publishing, London.

Sun, G., Gray, K. R. and Biddlestone, A. J. (1998a). Treatment of agricultural wastewater in downflow reed beds: Experimental trials and mathematical model. Agricultural Engineering Research, 69, 63-71

Sun, G., Gray, K. R. and Biddlestone, A. J. (1998b). Treatment of agricultural and domestic effluents in constructed downflow reed beds employing recirculation. Environmental Technology, 19, 529-536

Sun, G., Zhao, Y. and Allen, S. (2005). Enhanced removal of organic matter and ammoniacal-nitrogen in a column experiment of tidal flow constructed wetland system. Biotechnology, 115, 189-197

Sun, G., Zhao, Y., Allen, S. and Copper, D. (2006). Generating 'Tide' in pilotscale constructed wetlands to enhance agricultural wastewater treatment. Engineering Life Science, 6, 560-565

Toner, P., Bowman, J., Clabby, K., Lucey, J., McGarrigle, M., Concannon, C., Clenaghan, C., Cunningham, P., Delaney, J., O’Boyle, S., MacGarthaigh, M., Craig, M., Quinn, R. (2005). Water quality in Ireland. Environmental Protection Agency, Co., Wexford, Ireland.

Tyrrel, S.F. and Leeds-Harrison, P.B. (2005). Treatment of dirty water from dairy farms using a soil-based batch recirculation system. Water Science \& Technology, 51, 73-79

Verhoeven, J.T.A. and Meuleman, A.F.M. (1999). Wetlands for wastewater treatment: opportunities and limitations. Ecological Engineering, 12, 5-12 
Weedon, C.M. (2003). Compact vertical flow constructed wetland systems - first two years performance. Water Science \& Technology, 48, 15-23.

Yang, Y. Zhao, Y.Q., Babatunde, A.O., Wang, L., Ren, Y.X. and Han, Y. (2006). Characteristics and mechanisms of phosphate adsorption on dewatered alum sludge. Separation and Purification Technology, 51, 193-200.

Zhao, Y.Q., Sun, G., and Allen, S.J. (2004). Anti-sized reed bed system for animal wastewater treatment: a comparative study. Water Research, 38, 2907-2917

Zhao, Y.Q., Babatunde, A.O., Razali, M. and Harthy, F. (2008). Use of dewatered alum sludge as a substrate in reed bed treatment systems for wastewater treatment. Environmental Science and Health, A 43, 105-110.

Zhao, XH., and Zhao, Y.Q. (2009) 'Investigation of phosphorus desorption from P-saturated alum sludge used as a substrate in constructed wetland'. Separation and Purification Technology, 66 (1):71-75 